10 5

\title{
Estimation of health and economic costs of air pollution over the Pearl River Delta region in China
}

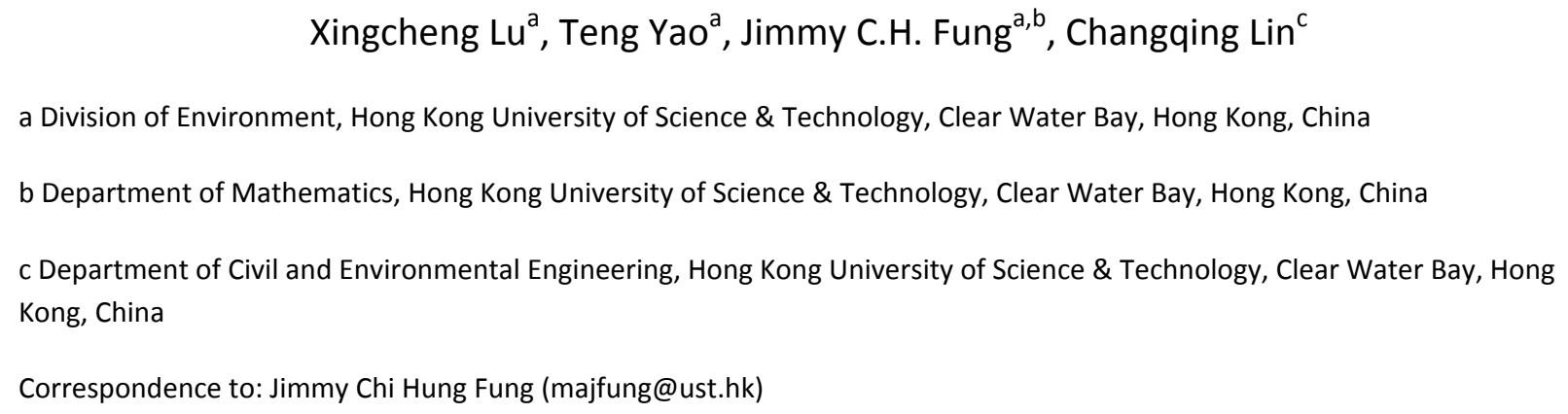

(1)
1 .

3

4 
Abstract:

The Pearl River Delta region (PRD) is the economic growth engine of China and also one of the most urbanized regions in the world. As a two-sided sword, rapid economic development causes air pollution and poses adverse health effects to the citizens in this area. This work estimated the negative health effects in the PRD caused by the four major ambient pollutants $\left(\mathrm{SO}_{2}, \mathrm{NO}_{2}, \mathrm{O}_{3}\right.$ and $\mathrm{PM}_{10}$ ) from 2010 to 2013 by using a log linear exposure-response function and the WRFCMAQ modeling system. Economic loss due to mortality and morbidity was evaluated by the value of statistical life (VSL) and cost of illness (COI) methods. The results show that the overall possible short-term all-cause mortality due to $\mathrm{NO}_{2}, \mathrm{O}_{3}$ and $\mathrm{PM}_{10}$ reached the highest in 2013 with the values being 13,217-22,800. The highest total economic loss, ranged from 14,768 to 25,305 million USD, occurred in 2013 and was equivalent to $1.4 \%-2.3 \%$ of the local gross domestic product. The monthly profile of cases of negative health effects varied by city and the types of ambient pollutants. The ratio of mortality attributed to air pollutants to total population was higher in urban areas than in rural areas. People living in the countryside should consider the possible adverse health effects of urban areas before they plan a move to the city. The results show that the health burden caused by the ambient pollutants over this region is serious and suggest that tighter control policies should be implemented in the future to reduce the level of air pollution.

\section{Keywords: Air pollution, Negative health effect, Economic loss, Urbanization, Pearl River Delta} (1) 


\section{Introduction:}

With the implementation of the Reform and Open Policy in the late 1970s, the Pearl River Delta region (PRD) has been transformed from an agricultural and fisheries economy to one of the major manufacturing hubs of the world. As one of the pioneering areas of reform in China, the PRD has also been called the "World's Factory" due to substantial investments made by foreign sources from around the world. Ever since the launch of the reform policy in 1979, the annual growth in the gross domestic product (GDP) over the last three decades has reached as much as $13.5 \%$ annually. Sustained and rapid economic growth has brought enormous wealth to the local residents, but with the simultaneous worsening of air quality, environmental and ecological conditions have deteriorated. This high-speed development is being achieved by building more and more energy-intensive industries and factories, and as a result, much larger amounts of coal are being consumed than in the past. At the same time, vehicle ownership is growing and increasing the amounts of $\mathrm{NO}_{\mathrm{x}}$ emitted into the atmosphere. Over the most recent 10 years, the PRD has been suffering from numerous air pollution issues, including episodes of high ozone $\left(\mathrm{O}_{3}\right)$, acid deposition and regional haze events, among others.

Given the continued deterioration of the ambient environment in this region, much observational-and numerical model-based research focusing on this area has been carried out in the most recent 10 years. For example, Kwok et al. (2010) used the Community Multi-scale Air Quality (CMAQ) model to simulate the gaseous and particulate pollutants in this region and performed a detailed analysis of spatial distribution and seasonal variation of ambient pollutants over this area. Wang et al. (2014) conducted a long-term trends study of $\mathrm{PM}_{2.5}$ from 2000 to 2010 and found that the National Air Quality standards were not met in any of these 11 years.

To quantify how ambient pollutants affect human beings, estimations of health burden that can provide information on mortality and economic loss due to air pollution in specific regions are highly needed. Many studies of this topic have been carried out in other regions around the world. For example, Fann et al. (2012a), Fann et al. (2012b) and Fann et al. (2013) applied model and observation data combining with BenMAP to analyze the mortality due to the exposure to $\mathrm{O}_{3}$ and $\mathrm{PM}_{2.5}$ in the US; Lelieveld et al. (2013) used a global model to evaluate premature mortality due to $\mathrm{PM}_{2.5}$ and $\mathrm{O}_{3}$; and Wang et al. (2015) applied WRF-CMAQ system to evaluate mortality and 
economic loss due to $\mathrm{PM}_{2.5}$ in the Yangtze River Delta region. In PRD, Huang et al. (2011) applied observational data to calculate the health burden caused by particulate matter in this region, and Ding et al. (2015) applied CMAQ-BenMAP to study the $\mathrm{PM}_{2.5}$ health burden in Guangzhou during the Asian Games. Besides particulate matter, the levels of $\mathrm{O}_{3}$, sulfur dioxide $\left(\mathrm{SO}_{2}\right)$ and nitrogen dioxide $\left(\mathrm{NO}_{2}\right)$ are also of concern over the PRD.

Previous studies only focused on the adverse health effects from a single pollutant, and thus we cannot grasp or compare the magnitude of mortality and morbidity caused by different pollutants. In this study, we applied the WRF-CMAQ modeling system to estimate and compare short-term mortality and economic loss due to four major ambient pollutants $\left(\mathrm{PM}_{10}, \mathrm{SO}_{2}, \mathrm{NO}_{2}\right.$ and $\left.\mathrm{O}_{3}\right)$ over the PRD during 2010 to 2013. The 'short-term mortality' means the mortality from short-term exposure in this article. This study can help us to answer four questions: 1) What is the magnitude of the estimated health burden (hospital admissions, outpatient visits and mortality and economic loss) due to the major air pollutants in the PRD?; 2) How has the health burden varied over the four study years under different yearly meteorological conditions?; 3) What are the monthly variations in mortality and morbidity due to the different pollutants?; and 4) What effects of urbanization on the health burden can be attributed to ambient pollutants?

\section{Methods:}

\subsection{Modeling System}

The WRF-SMOKE (Sparse Matrix Operator Kernel Emissions)-CMAQ air quality system was used to simulate the air quality conditions from 2010 through 2013 over the PRD area. We applied a one-way nested method for the simulation, and the grid resolutions were $27 \mathrm{~km}, 9 \mathrm{~km}$ and $3 \mathrm{k} \mathrm{m}$. Details of the domain extent can be found in Figure 1. We applied domain $3(3 \mathrm{~km})$ to study the health burden. The WRF configuration can be found in Yao et al. (2014). For the CMAQ setting, cloud_acm_ae5, aero5 and cb05 were chosen as the cloud module, aerosol module and gas phase mechanism, respectively, in the simulation. To better catch the Asian background concentrations of the pollutants, pre-generated GEOS-Chem outputs were used for initial and boundary conditions for domain $1(27 \mathrm{~km})$. The INTEX-B Asian emission inventory 
(Zhang et al., 2009) was used for domain 1 and domain $2(9 \mathrm{~km})$, whereas a highly resolved PRD regional emission inventory was prepared for domain 3 (Zheng et al., 2009). MEGAN (Model of Emissions of Gases and Aerosols from Nature) was used to generate the biogenic volatile organic compound emission for all three domains. The CMAQ model performance matrix for daily pollutants in the PRD is shown in Table S1. In general, our results were comparable to those of other similar studies of this region (Kwok et al., 2010; Wu et al., 2012 and Li et al., 2012).

\subsection{C-R Functions}

We calculated the air pollution associated with outpatient visits, hospital admissions and shortterm premature mortality by applying log-linear C-R functions (Equation 1). This function can be used only to estimate negative health effect (e.g., respiratory mortality and cardiovascular mortality) from diseases for which epidemiological studies already exist.

$$
\Delta y=y_{0}\left(e^{\beta \Delta x}-1\right) P o p
$$

where $\Delta \mathrm{y}$ represents premature mortality or hospital admission caused by the related ambient pollutant. $\mathrm{y}_{\mathrm{o}}$ is the baseline incidence rate for specific diseases per unit population. Exponential factor $\beta$ is the exposure-response coefficient calculated via $\beta=\ln (\mathrm{RR}) / \Delta \mathrm{x}$ and $\mathrm{ER}(\%)=(\mathrm{RR}-$ 1)*100\%. Relative risk (RR) and Excess risk (ER) for related health endpoint can be found in the epidemiological studies. $\Delta \mathrm{x}$ in equation 1 represents the difference between the true exposure concentration and the threshold concentration below which no adverse health effect occurs for the ambient pollutant. However, it is still controversial to define the safe threshold for ambient pollutants. Hence, in this study, we applied the natural background concentration for the lower limit of related ambient pollutants (Fiore et al., 2002; WHO, 2000; Veira et al., 2013), as listed in table S3. Pop is the spatial distribution of the population over the PRD in domain 3.

The rates of hospital outpatient visits, hospital admissions and mortality were acquired from the China Statistical Yearbook (2010-2013). The health endpoints we evaluated included cardiovascular mortality, respiratory mortality, all-cause outpatient visits and all-cause hospital admissions, as shown in Table S4. The three annual mortality rates (first three rows) are for the 
whole of China, and the annual rates of outpatient visits and hospital admissions (fourth and fifth rows) are for Guangdong Province. This table shows that the rates of hospital outpatient visits and hospital admissions increased gradually from 2010 to 2013 in Guangdong.

The exposure-response coefficient derived from excess risk is the core for quantitative evaluation of health effects caused by air pollutants. Here, we applied the coefficient reported in local epidemiological studies. Because few $\mathrm{O}_{3}$-related epidemiological studies for morbidity have been done in China, we did not evaluate hospital admissions and outpatient visits attributed to $\mathrm{O}_{3}$. Thus, we evaluated the short-term mortality caused by exposure to $\mathrm{PM}_{10}, \mathrm{SO}_{2}, \mathrm{NO}_{2}$ and $\mathrm{O}_{3}$ and the numbers of hospital admissions and outpatient visits due to $\mathrm{SO}_{2}, \mathrm{NO}_{2}$ and $\mathrm{PM}_{10}$ in this study. These values are all listed in Table 1. The excess risks of total mortality, cardiovascular mortality and respiratory mortality for all ages were taken from Shang et al. (2013); the coefficients of total outpatient visits and total hospital admissions for all ages were from Chen et al. (2011), Cao et al. (2009) and Chen et al. (2010).

In this study, besides comparing the adverse health effect exerted by different pollutants, we also calculated the total health impact caused by all the four ambient pollutants. However, direct addition may cause overlapping issue because the negative health case may associate with two or more ambient pollutants. One straightforward method is to use the exposure-response coefficients derived from the multi-pollutant model. But, up to now, few studies in this region applied four-pollutant model $\left(\mathrm{PM}_{10}, \mathrm{SO}_{2}, \mathrm{NO}_{2}\right.$ and $\left.\mathrm{O}_{3}\right)$ to calculate the concentration-response coefficients. Wong et al. (2002) used the four-pollutant model for the relative risk calculation focusing on Hong Kong. However, except the respiratory mortality, the other three health endpoints they calculated were not the same as the ones that we analyzed in this study. According to Kan et al. (2010), the excess risk of $\mathrm{SO}_{2}$ almost decreased to zero and became statistically insignificant after the adjustment for $\mathrm{NO}_{2}$ in Hong Kong. The ambient concentration of $\mathrm{SO}_{2}$ in PRD region was low, hence, we did not consider $\mathrm{SO}_{2}$ for the total health effect calculation. Shang et al. (2013) did not adjust the excess risk for $\mathrm{NO}_{2}$ and $\mathrm{PM}_{10}$. Hence, we used the adjusted excess risk for these two pollutants in Qian et al. $(2007 \mathrm{a})(1.14(0.45,1.85))$ and Qian et al. (2007b) $(0.14(-0.07,0.36))$. These two studies were included in the meta-analysis in Shang et al. (2013). The results from Ito et al. (2005) suggested that $\mathrm{O}_{3}$ and PM contributed 
independently to mortality. Zhang et al. (2006) showed that $\mathrm{O}_{3}$ has low correlation with the other three ambient pollutants and after the adjustment for other pollutants, the association between $\mathrm{O}_{3}$ and daily mortality was still statistically significant. Therefore, based on the facts listed above, we used the formula below for total health effect estimation:

$$
\left(\mathrm{PM}_{10}{ }^{\mathrm{a}}+\mathrm{NO}_{2}{ }^{\mathrm{a}} \sim \mathrm{PM}_{10}{ }^{\mathrm{a}}+\mathrm{NO}_{2}{ }^{\mathrm{a}}+\mathrm{O}_{3}{ }^{\mathrm{b}}\right)
$$

Where $\mathrm{PM}_{10}{ }^{\mathrm{a}}, \mathrm{NO}_{2}{ }^{\mathrm{a}}$ and $\mathrm{O}_{3}{ }^{\mathrm{b}}$ represent the adverse health cases caused by adjusted $\mathrm{PM}_{10}$, adjusted $\mathrm{NO}_{2}$ and none-adjusted $\mathrm{O}_{3}$. Note that the result is a range due to the $\mathrm{O}_{3}$ effect cannot be neglected or added directly. Since the adjusted excess risk for the outpatient visit had not been shown in the literature we cited, hence, the combined morbidity effect ranged from the adverse case caused by $\mathrm{NO}_{2}$ to the adverse case caused by both $\mathrm{NO}_{2}$ and $\mathrm{PM}_{10}$. Also note that the expression listed above does not represent the true 'upper bound' and 'lower bound' of the combined health effect caused by air pollution. The overall health effect estimation needs to include the long term effect, which is beyond the range of our study.

The population data we applied was from the LandScan (2008) ${ }^{\mathrm{TM}}$ High Resolution Global Population Data Set. Because this was the population for 2008, the ratios for the total population between the target years (2010, 2011, 2012 and 2013) and 2008 for each city were derived and multiplied for the grid cell within the domain for each year's calculation.

\subsection{Economic Loss Calculation}

We applied the VSL and COI methods to estimate the economic loss due to mortality and hospital visits/admissions. The VSL is the economic value assigned to a person. According to a report published by OECD, the VSL for China was 0.98 million USD in 2010. Other three years' VSLs were estimated based on the Consumer Price Index (CPI) in each year. The VSLs for 2011, 2012 and 2013 were 1.03 million, 1.06 million and 1.08 million USD.

The COI for all-cause outpatient visits and hospital admissions was calculated by Equation 3 (Huang et al., 2012). The COI method was used to calculate both the pharmaceutical and hospitalization costs and the loss of income during sick leave due to illness.

$$
\mathrm{C}=\left(\mathrm{C}_{\mathrm{m}}+\mathrm{GDP}_{\mathrm{d}} * \mathrm{~T}\right) * \Delta \mathrm{y}
$$


where $\mathrm{C}$ is the total cost of outpatient visits or hospital admissions due to exposure to ambient air pollutants, $\mathrm{C}_{\mathrm{m}}$ represents the cost for medical treatment for each case, $\mathrm{GDP}_{\mathrm{d}}$ is the GDP per capita per day, $\mathrm{T}$ is the labor time lost due to illness and $\Delta \mathrm{y}$ represents the number of cases of health issues (hospital admissions/outpatient visits). Table S5 shows the $\mathrm{C}_{\mathrm{m}}$ values for outpatient visits and hospital admissions. The unit cost for all four years was cited from the China Public Health Statistics Yearbook. The medical system for Hong Kong is not the same as that for mainland China. However, no expenditures for outpatient visits/hospital admissions could be found in the Hong Kong Government Yearbook; hence, we applied the same cost listed in Table S5 for Hong Kong. According to the health statistical yearbook, the labor time lost due to hospital admission is around 10.5 days, 10.3 days, 10.0 days and 9.5 days for 2010, 2011, 2012 and 2013, respectively (China Public Health Statistics Yearbook), and the time lost due to outpatient visits is about 0.5 days.

\section{Results}

\subsection{Adverse Health Effects}

Table 2 presents the short-term all-cause mortality, cardiovascular mortality, respiratory mortality, all-cause outpatient visits and all-cause hospital admissions due to exposure to the four ambient pollutants studied. Over the PRD, the estimated premature mortality and numbers of outpatient visits and hospital admissions were greatest for $\mathrm{NO}_{2}$ and reached 12,240 (11,21413,263) cases for all-cause mortality, 4,973 (4,333-5,576) cases for cardiovascular mortality, 1,627 (1,330-1,912) cases for respiratory mortality, 5,227,714 (1,343,518-9,150,103) outpatient visits and 159,833 (16,437-298,023) hospital admissions in 2013. The reason for this is that the coefficient of $\mathrm{NO}_{2}$ for adverse health effects is much larger than that for the other pollutants (Table 2). $\mathrm{O}_{3}$ was the second most harmful pollutant, causing $11,471(9,102-13,803)$ cases of premature all-cause mortality, 3,880 (2,517-5,146) cases of cardiovascular mortality and 1,585 $(1,047-2,090)$ cases of respiratory mortality in 2011 . The short-term respiratory mortality caused by $\mathrm{O}_{3}$ in years 2011 and 2012 was larger than that caused by $\mathrm{NO}_{2}$. Compared to particulate matter, gaseous pollutants resulted in more cases of mortality and morbidity. Yearly comparisons 
212 showed that the number of cases of negative health effects caused by ambient pollutants (except

213 for $\mathrm{O}_{3}$ ) was greater in year 2013 than in the other three years and the reasons will be analyzed in

214 the discussion part.

215 Table 3 presents the four-year average number of cases of mortality and morbidity caused by the 216 ambient pollutants in each city over the PRD region. Details of each year's estimates are shown

217 in Tables S6-S9 of the supplemental material. Among the 10 cities, Guangzhou was the most

218 affected by the ambient pollutants. The all-cause mortality associated with $\mathrm{SO}_{2}, \mathrm{PM}_{10}, \mathrm{NO}_{2}$ and $219 \mathrm{O}_{3}$ in Guangzhou was 1,872 (1,642-2,098), 3,689 (3,381-3,995), 1,858 (1,474-2,237) and 1,271

$220(1,116-1,389)$ respectively.

\section{$221 \quad 3.2$ Monthly Variation}

222 The premature mortality and morbidity attributed to the ambient pollutants are affected by 223 several factors, such as pollutant emissions, pollutant species and meteorological condition. As 224 shown in Tables S10-S13 in the supplemental material, the four-year short-term premature 225 mortality and morbidity for each city varied by month. Also, the monthly concentration profiles 226 of the four ambient pollutants were different, and thus the mortality and morbidity over the 12 227 months was not the same for the four ambient pollutants. Because the monthly profiles for 228 different negative health effects were similar, we applied short-term all-cause mortality as an 229 example for purposes of analysis. To compare the trend in monthly variation between the 230 different pollutants, each month's number of mortality cases in each city for the specific 231 pollutant was divided by the 12-month average all-cause mortality attributed to that pollutant, as 232 shown in Figure S5.

233 The cases of all-cause mortality for $\mathrm{SO}_{2}$ peaked in August and July for Guangzhou, Dongguan 234 and Shenzhen. Guangzhou's cases peaked in July at which time the average reached 168 (147235 188), and those for Shenzhen and Hong Kong peaked in August, when mortality reached 119 236 (104-133) and 66 (58-74), respectively; In Dongguan, the mortality also peaked in August, with 23782 (72-92) cases. However, the short-term mortality peak for some cities occurred in the winter, 238 e.g., in January for Foshan and Zhongshan and December for Jiangmen. These differences 239 between cities were caused by the location of the emission sources and the prevailing wind 
direction. For example, the peaks for Shenzhen and Hong Kong in August were caused by $\mathrm{SO}_{2}$ from marine emissions blown up by the southerly winds. It should also be noted that the monthly variation in magnitude for each city was different. For instance, the variation in Guangzhou was small, and the difference between the peak and lowest case number was just around $20 \%$ of the peak case number. The variation in magnitude was large for Jiangmen, with the peak number in December being four times larger than the lowest case number in July. The changing trend for other cities can also be found in Figure S5.

The temporal profile of all-cause mortality attributed to $\mathrm{NO}_{2}$ was quite different from that of $\mathrm{SO}_{2}$. The peak for the mortality associated with $\mathrm{NO}_{2}$ appeared in winter in most of the cities over this region. For example, the short-term all-cause mortality peaks for Shenzhen, Foshan and Hong Kong occurred in January, with case numbers of 242 (222-263), 211 (193-228) and 163 (150177), respectively. In contrast, the peaks for Guangzhou and Dongguan occurred in February, with respective case numbers of 400 (367-433) and 134 (123-145). As Figure S5 shows, the temporal variation in magnitude was large in Foshan, Jiangmen and Zhuhai but small in Shenzhen, Guangzhou and Hong Kong.

For $\mathrm{O}_{3}$, the trough of short-term all-cause mortality fell between June and July because the monsoon season dominates the summer with heavy precipitation and thick clouds in southern China, which are not favorable for $\mathrm{O}_{3}$ production (Wang et al. 2011). The peak in $\mathrm{O}_{3}$ production causing premature mortality for all 10 cities occurred in March. For example, the cases of allcause mortality in this month for Guangzhou, Shenzhen and Dongguan reached 205 (163-246), 189 (150-228) and 166 (132-199), respectively, primarily due to the favorable meteorological conditions for $\mathrm{O} 3$ formation and its long-range transportation. $\mathrm{O}_{3}$ is a secondary pollutant, and in the transition season, northerly winds could bring $\mathrm{O}_{3}$ formed in other areas into the PRD. Thus, the concentration of $\mathrm{O}_{3}$ increased and caused more mortality in winter compared with that in summer.

The peak in all-cause mortality exerted by respirable particulate matter occurred in January. This was also due to the characteristics of the seasonal wind field in the PRD. Secondary pollutants comprise a substantial part of the particulate matter, and the lifetime of these pollutants can be up to several days. Similar to $\mathrm{O}_{3}$, the northerly wind brought particulate matter into this region from 
other places, such as the Yangtze River Delta. During January, the cases of all-cause mortality due to $\mathrm{PM}_{10}$ in Guangzhou, Shenzhen and Foshan reached 154 (136-168), 94 (83-103) and 95 (83-104), respectively. Mortality associated with $\mathrm{PM}_{10}$ was lowest in July for all of the cities in the region. For instance, the cases of all-cause mortality related to exposure to $\mathrm{PM}_{10}$ were 61 (5366) in Guangzhou, 23 (20-25) in Shenzhen and 21 (18-23) in Foshan, less than half the number caused by this pollutant in January.

In some cities, such as Jiangmen, Zhongshan and Zhuhai, the monthly patterns of all-cause mortality for $\mathrm{SO}_{2}, \mathrm{NO}_{2}$ and $\mathrm{PM}_{10}$ are similar. $\mathrm{SO}_{2}$ and $\mathrm{NO}_{2}$ are primary pollutants, and their lifetimes are both around one day, so it was unlikely that they came from other regions. All three of these cities are located in the southern part of the PRD, and they are all downwind of the major PRD cities, such as Guangzhou, Shenzhen and Foshan. Therefore, in winter, when the prevalent wind direction is from north, $\mathrm{SO}_{2}$ and $\mathrm{NO}_{2}$ could come down with the wind, and the concentration of these two pollutants would increase. As a result, short-term premature all-cause mortality led by these two pollutants rose together with the cases of negative health attributed to particulate matter.

\subsection{Economic Loss}

According to the VSL and COI methods, the total economic loss due to mortality and morbidity caused by air pollution in the whole PRD region reached the top in 2013 with the estimated value of $(14,768-25,305)$ millions USD. In each category, the cost caused by all-cause mortality, outpatient visits and hospital admission all reached the most in 2013, as shown in table 4. Each city's costs of mortality and morbidity can be found in Tables S14 in the supplemental material. For the VSL estimate of all-cause mortality cost, Guangzhou and Shenzhen were the two cities whose cost was over 2000 millions USD in the four years. This cost for Foshan exceeded 2,000 millions USD in 2013. This cost was low in Zhuhai and Zhaoqing and the values were only (172$483)$ and (168-599) million USD respectively in 2013. The health cost derived from the all-cause mortality increased gradually through these four years in most of the cities, except Zhuhai and Zhongshan. The trend and relative amount of cost generated by other health endpoints was similar with all-cause mortality. 


\section{Discussions}

298

299

300

301

302

303

304

305

306

307

308

309

310

311

312

313

314

315

316

317

318

319

320

321

322

323

324

325

\subsection{Health Burden Analysis in PRD Area}

As mentioned above, Guangzhou was the city that suffered the most from the ambient pollutants in this area. Most population in the region, substantial amount of pollutant emission and pollutant regional transport were three factors that make Guangzhou suffer the most from ambient pollutants. Huang et al. (2012) calculated the mortality and morbidity attributed to $\mathrm{PM}_{10}$ in the PRD and found that the short-term all-cause mortality in Guangzhou was 1130 (337-1,929) cases in 2006. Our result is comparable to their result. Shenzhen is the other city that also suffered heavily from ambient pollution: the short-term all-cause mortality caused by the four pollutants accounted for around $15 \%$ to $20 \%$ of the all-cause mortality cases in the whole PRD. Shenzhen was also heavily influenced by its local sources of emissions, especially by the mobile sources of emissions. This city was influenced by the regional ambient pollution coming from Hong Kong when the predominant wind direction was southeasterly or southwesterly during the transition and monsoon seasons (late spring, summer and early autumn) in this region. Zhaoqing and Zhuhai were the cities that suffered the least over the PRD: negative health cases due to ambient pollution in these two cities accounted for only around $0.5 \%$ to $3.0 \%$ of all cases in the region. The amounts of pollutants emitted for these two cities were relatively small when compared to those in other cities in the PRD, and their populations were also smaller than those of the other major cities in the region. The spatial distribution of all-cause mortality in 2013 is shown in Figure 2, and that for the other three years can be found in Figures S1-S3 of the supplemental material. From the spatial mapping aspect, the cases of mortality were clustered in the city centers in Guangzhou, Shenzhen and Hong Kong. As the spatial mapping data show, the annual average spatial difference in health burden was not large over the four years under different meteorological conditions. The meteorological conditions did not change that much during these four years. This implies that the spatial distribution of the health burden in this area was not shaped primarily by meteorological conditions but by the location of the emissions and population distribution. The clear monthly variation implies that the government should implement more strict pollution control policy in winter and people should properly reduce the outdoor physical exercise in this season. 
As mentioned in the result part, the adverse health effect associated with ambient pollutants reached the top in the year 2013. This is mainly due to the increasing baseline incidence rate of different health endpoints, population growth and differences in yearly pollutant concentrations within the region. According to the model simulation results, the average $\mathrm{O}_{3}$ concentration in 2011 was larger than that in the other three years, and this caused the $\mathrm{O}_{3}$-related cardiovascular mortality and all-cause mortality to be the largest in 2011. Respiratory mortality was not the same as that of these two health endpoints; the baseline incidence rate for respiratory mortality was the lowest in year 2011. The number of outpatient visits was much larger than the number of cases of negative health effects related to the other health endpoints primarily because the baseline incidence rate for hospital outpatient visits is much larger than the annual rate for the other health endpoints. As shown in Table 1, the annual rate of outpatient visits is 3-4 orders of magnitude larger than the three mortality endpoints and 1-2 orders of magnitude larger than the hospital admission endpoint. Also, one issue is that the all-cause mortality associated with air pollutants is much larger than the sum of the cardiovascular mortality and respiratory mortality in some of the cities. This is partly because in China, the top 15 causes of premature mortality include lung, liver, stomach, oesophageal, and colorectal cancer, which is quite different from other countries (Yang et al., 2013). It may also cause by the overestimation of the all-cause mortality excess risk and the underestimation of the cardiovascular mortality / respiratory mortality excess risk. Therefore, more work is needed in the future to find out this gap.

The economic loss associated with ambient pollutants also reached the top in 2013. The ratio of total economic loss (all-cause mortality, outpatient visits and hospital admissions) caused by ambient pollutants to total regional GDP ranged from $1.4 \%$ to $2.3 \%$ over the whole PRD during 2013. In this year, the expenditures for technology innovation, energy saving and culture, sport and media over Guangdong province accounted for $0.54 \%, 0.48 \%$ and $0.23 \%$ of the total GDP, respectively. Hence, from the aspects of both health and economic development, it is of great importance for local government to continue to draw up pertinent control policies to further tackle the issue of air pollution. We want to emphasize that human life is invaluable, and it cannot be labelled with a price. We attempted to present the adverse effects caused by ambient pollutants in a straightforward manner and thus applied the VSL and COI methods to quantify 
these effects. Our purpose was to heighten public awareness of the harmfulness of ambient pollutants in a more easily understandable way.

Among the four pollutants, $\mathrm{NO}_{2}$ caused the most mortality and morbidity over the four years, which is much larger than those exerted by $\mathrm{PM}_{10}$ and $\mathrm{SO}_{2}$. This is mainly due to four reasons: 1 , the excess risk for $\mathrm{NO}_{2}$ is the largest among the four pollutants according to Shang et al. (2013); 2, the relative risk of $\mathrm{O}_{3}$ is larger than that for $\mathrm{PM}_{10}$ and $\mathrm{SO}_{2} .3$, the excess risk for $\mathrm{PM}_{10}$ is the lowest in the four pollutants; 4, the $\mathrm{SO}_{2}$ concentration is relatively low (only around 10ppb) when compared to other pollutants. Chen et al. (2010) stated that the observed health effects attributed to the gaseous pollutants might actually be a result of exposures to fine particles or traffic-related emissions, which may result in the overestimation of the excess risk of $\mathrm{NO}_{2}$. Therefore, from the health perspective, the government should place traffic emission control at the top of the list when drawing up a systematic air pollution control policy. The reduction of traffic emission can also help to decrease the formation of secondary particulate matter (nitrates) in this region. However, according to $\mathrm{Li}$ et al. (2013), $\mathrm{O}_{3}$ is formed under different conditions (volatile organic compound-limited \& $\mathrm{NO}_{\mathrm{x}}$-limited) in different seasons over this region. Therefore, it is possible that the traffic control $\left(\mathrm{NO}_{\mathrm{x}}\right.$ control) would result in the $\mathrm{O}_{3}$ concentration rising and causing increases in mortality and morbidity due to this rise. Hence, more cost-benefit analysis is needed for the future review of a traffic emission control policy and its implementation.

\subsection{Urbanization and Industrialization Effect}

After the implementation of an open policy in the PRD, urbanization proceeded over this area at an unbelievable speed, especially in Guangzhou and Shenzhen. Urbanization can increase convenience for the local citizens by providing a well-equipped infrastructure and complete traffic network. At the same time, however, urbanization can also contribute to air pollution by increasing the consumption of energy and construction materials. Also, densely constructed urban areas can trap pollutants by decreasing wind speeds (Ng et al., 2011 and Yim et al., 2014). 
382 Therefore, it is important to determine how urbanization is influencing public health in this 383 region.

384 Figure S6-S9 show the correlation between urban fraction and the ratio of all-cause mortality to total population for each grid cell over the PRD in the four years. The urban fraction in our study represents the urban percentage in each grid cell of domain 3 in the CMAQ model. Mapping of the urban fraction is shown in Figure S4 in the supplemental material. Details on the land-use map we used can be found in Lo et al. (2006). In general, the increasing magnitude of this ratio was more apparent for $\mathrm{SO}_{2}$ and $\mathrm{NO}_{2}$ than for $\mathrm{PM}_{10}$ with the increasing urban fraction. $\mathrm{NO}_{2}$ was mainly emitted by vehicles, and most of them were clustered in urban regions. Although vehicles can also emit $\mathrm{SO}_{2}$, substantial amounts of this pollutant were emitted by power plants located at the edges of the city borders. As a result, the correlation between the mortality caused by $\mathrm{NO}_{2}$ and the urban fraction is larger than that for $\mathrm{SO}_{2}$. Although $\mathrm{PM}_{10}$ could be emitted by illegal sources in urban regions, a large percentage of it came from long-range transportation outside this region (Wu et al., 2013). Thus, the mortality caused by $\mathrm{PM}_{10}$ did not change that much when the urbanization fraction increased as compared with the mortality caused by $\mathrm{SO}_{2}$ and $\mathrm{NO}_{2} . \mathrm{O}_{3}$ is a secondary ambient pollutant, and it can be titrated by NO at the roadside. Hence, in the dense urban regions in which $\mathrm{NO}_{\mathrm{x}}$ emissions were large, the $\mathrm{O}_{3}$ concentration would decrease, and thus the mortality caused by $\mathrm{O}_{3}$ correlated negatively with the urban fraction. Another reason for this negative correlation was that $\mathrm{O}_{3}$ could not be emitted by any source in the urban area. The $\mathrm{O}_{3}$ concentration would be lower due to the height of the planetary boundary layer over urban areas is higher than that over rural areas. The correlations for the other three years can be found in the 403 supplemental material. Because the correlation between other health endpoints and urban 404 fraction was similar to that for all-cause mortality, these results were not shown.

405 The correlation between the ratio of total all-cause mortality caused by the four pollutants to 406 urban fraction at each grid cell is shown in Figure 3. Each point represents the average ratio for a 407 specific urban fraction range. In general, the urban fraction and all-cause mortality showed 408 positive and significant correlation, although the mortality caused by $\mathrm{O}_{3}$ was less in the urban 409 than rural areas. The people living in places in the PRD in which the urban fraction was between $410 \quad 0$ and 0.1 had the least health risk caused by the major ambient pollutants. The mortality ratio 
411 increase gradually with the increase of urban fraction. The people living in locations whose 412 urban fraction was over 0.9 suffered the highest health risk caused by the four pollutants, having 413 double the mortality rate of those living in areas in which the urban fraction ranged from 0 to 0.1. 414 In China, some people living in rural areas always try to move to the city because they believe 415 that they can earn a higher income in an urban area. However, according to this study, the health 416 risk caused by air pollution in urban areas was larger than that in rural areas. As a result, personal 417 medical expenditures would increase.

418 Industrialization is the driving force for urbanization and urbanization is the inevitable results of 419 industrialization. In PRD region, as the industry process goes on, more and more industry 420 companies moved to this region. Transportation route expanded and the emission from vehicle, 421 train and vessel increased as well. The primary pollutants in PRD region included $\mathrm{SO}_{2}, \mathrm{NO}_{\mathrm{x}}$ and $422 \mathrm{PM}_{10}$ and the three major emission sources are power plant emission, industry emission and 423 mobile emission. According to Zheng et al. (2009), the power plant emission, industry emission 424 and mobile emission contributed around 50\%, $40 \%$ and $10 \%$ of $\mathrm{SO}_{2}$ emission. The power plant 425 emission, industry emission and mobile emission were responsible for around 40\%, $10 \%$ and 426 $40 \%$ of total $\mathrm{NO}_{\mathrm{x}}$. While for $\mathrm{PM}_{10}$, power plant emission took up around 20\%, industry emission 427 took up 50\% and mobile emission took up $20 \%$ respectively. The three pollutants emitted from 428 residential fuel combustion was less than $1 \%$.

429 However, the emission percentage cannot reveal the source contribution in ambient pollutants, 430 especially it cannot reveal the regional transport contribution. Wu et al. (2013) found that the 431 super-regional (outside PRD region) and mobile emission contribution to ambient $\mathrm{PM}_{2.5}$ was over $40 \%$ and $20 \%$ in this region. Li et al. (2012) found that in high ozone episode day the superregional contribution was over 60\%. Lu et al. (2015) did a source apportionment case study for wet deposition and found that power plant emission and super-regional contribution were the major contributors for sulfate and nitrate. Recently, Lu et al. (2016) found that heavy duty diesel vehicle and industrial point source contributed $30 \%$ and $19 \%$ of local $\mathrm{NO}_{\mathrm{x}}$ in this region. Hence, 438 further control the vehicle number and supervise the production process of industry companies 439 (e.g. whether the emission exceeds the cap). At the same time, since substantial amount of 
440

pollutant came from long-range transportation, enhanced cross-broader cooperation with other provinces is also highly needed.

\subsection{Uncertainty Analysis}

There is uncertainty about the results of our estimation of the health burden in relation to the following: ambient pollutant concentrations simulated by the CMAQ model, baseline incidence rates, exposed population, exposure-response coefficients and the economic loss calculation method. The chemical transport model can provide spatial ambient pollutant concentrations at each hour during the simulation period so that we can estimate the health burden over the whole PRD without merely applying point observation data. The simulation process cannot fully reveal the true condition due to the error derived by emission inventory, simplified parameterization schemes and the meteorological field. Inaccuracy caused by these processes mentioned above derived the uncertainty of pollutant concentrations simulated by the CMAQ model. For the baseline incidence rate, although we acquired this data from the China Statistical Yearbook, the values varied by city, by district and even by $3 \times 3 \mathrm{~km}$ grid cell due to different medical conditions. The population data we applied was generated from a 2008 spatial distribution and each city's total population during the study period. In reality, the spatial distribution of population would change each year, thus causing uncertainty in relation to this factor.

The exposure-response coefficient, the core element for estimating mortality and morbidity, was derived from relative risk. The exposure-response coefficients for all-cause mortality, cardiovascular mortality and respiratory mortality were cited from Shang et al. (2013), which was based on China Air Pollution and Health Effect Study (CAPES) and meta-analysis. The morbidity related exposure-response coefficients were derived from two epidemiologic studies with a temporal coverage of two years (2005-2007) in Shanghai, which is also suffered from air pollution issue as PRD area. The excess risks we used in this study are different from those in North America and Europe. For example, Chiusolo et al. (2011) reported that $10 \mu \mathrm{g} / \mathrm{m} 3$ increase of $\mathrm{NO}_{2}$ is associated with 2.09 (0.96-3.24) percent increase of all-cause mortality, 2.63 (1.533.75) percent increase of cardiovascular mortality and $3.48(0.75-6.29)$ percent increase of 
468

469

470

471

472

473

474

475

476

477

478

479

480

481

482

483

484

485

486

487

488

489

490

491

492

493

494

495

496

respiratory mortality in Italy. The difference is attributed to different medical condition, air pollution level, statistical methods used for analysis and so on. Wang et al. (2006) stated that it was not suitable to apply the relative risk from other countries to a region whose medical conditions and pollution levels varied significantly. Martenies et al. (2015) also mentioned that assessments of health effects should use local data. Therefore, in this study, we used the exposure-response coefficient for related health endpoints originating from Chinese epidemiological studies mentioned before. Although this can avoid the cross-country difference, the uncertainty caused by the variation in medical conditions between different cities is unavoidable. Observed health effects due to the gaseous pollutants might actually be a result of exposures to the particulate matter, hence, the excess risk for related gaseous pollutant may be overestimated. In this study, we used the natural background concentration as the threshold for the health impact estimation. However, it has not been confirmed that if the safe thresholds exist and our results will be underestimated if adverse health effects still exist below the specific threshold we set. The same condition will also happen if the background concentration is overestimated.

Uncertainty also exists in the economic estimation method we applied. Given the lack of local data, the VSL data applied in this study was generated from the VSL data in OECD report together with local CPI data (Voorhees et al., 2014). The costs of outpatient visits and hospital admissions were obtained from the China Statistical Yearbook. The medical system and economic conditions are not the same between the Hong Kong SAR and mainland China. However, due to the lack of related data for Hong Kong, we applied the same data used with other mainland cities in the PRD to the calculation of Hong Kong's COI. The economic loss estimation based on VSL method might be overestimated due to the fact that the air pollutants may be just one of the factors that worsen the existed diseases. More work needed to be carried out to verify whether it is reasonable to attribute the full VSL to a death associated with air pollutants.

The uncertainties mentioned here are common in related studies that estimate health burden, and they remain unavoidable until the results of more detailed and local epidemiological studies are published. However, because our model performance was reliable and the data we applied were 
497 all from China, we believe that our study can provide an overall picture of the health burden

498 caused by air pollution, which can be used for the formation of future control policies in the PRD. 499 Also note that the uncertainty we discuss in this section is for the short-term health impact 500 estimation, for overall health impact, the long-term exposure should also be taken into account.

\section{Conclusion}

503 We applied WRF-CMAQ modeling to estimate and compare the health burden caused by four ambient pollutants $\left(\mathrm{SO}_{2}, \mathrm{NO}_{2}, \mathrm{O}_{3}\right.$ and $\left.\mathrm{PM}_{10}\right)$ in the PRD during 2010-2013. Among the four pollutants, $\mathrm{NO}_{2}$ caused the most cases of mortality and morbidity over the whole region. Of the 10 cities studied, Guangzhou was most seriously influenced by ambient pollutants. Because the emission and formation processes for each pollutant were different, the temporal patterns of mortality and morbidity for each city were also different. Substantial amounts of $\mathrm{PM}_{10}$ came from long-range transportation sources. Influenced by the northern wind in winter, high concentrations of particulate matter came from northern areas outside the PRD, resulting in increased cases of mortality and morbidity due to this pollutant. Although the cases of negative

512 health effects did not vary greatly each month for some primary pollutants such as $\mathrm{SO}_{2}$, mortality 513 and morbidity caused by $\mathrm{SO}_{2}$ in Shenzhen and Dongguan were high. The estimation of economic 514 loss due to negative health effects was the highest in 2013, ranged from 14,768 to 25,305 million 515 USD. The ratio of economic loss to GDP over the PRD ranged from $1.4 \%$ to $2.3 \%$, which was 516 larger than some important government expenditures. Urbanization and industrialization process 517 played an important role in affecting human health in this region. As the urban fraction increased, 518 the ratio of mortality attributed to ambient pollutants to total population also increased. Citizens 519 need to think twice before they plan to move to an urban area. Our results indicate that air 520 pollution caused numerous cases of mortality and morbidity over the PRD. Hence, more 521 stringent control policies must be drawn up to better guarantee health and economic benefits to 522 its citizens. In order to understand the overall health impact associated with ambient pollutants in this region, the long-term exposure related study is highly needed in this region. 


\section{Acknowledgement:}

526 This work was supported by the National Science Foundation of China (No. 41375103),

527 NSFC/RGC Grant N_HKUST631/05, UGC Special Equipment Grant (SEG_HKUST07), the

528 UGC Special Research Fund Initiatives (SRFI11IO01), ECF project (ECWW09EG04), NSFC-

529 GD Grant U1033001, and the Fok Ying Tung Graduate School (NRC06/07.SC01).

\section{References:}

532 Cao, J., Li, W., Tan, J., Song, W., Xu, X., Jiang, C., Chen, G., Chen, R., Ma, W., Chen, B., \& 533 Kan, H. (2009). Association of ambient air pollution with hospital outpatient and emergency 534 room visits in Shanghai, China. Science of the total environment, 407(21), 5531-5536.

535 Chen, R., Chu, C., Tan, J., Cao, J., Song, W., Xu, X., Jiang, C., Ma, W., Yang, C., Chen, B., Gui, 536 Y., \& Kan, H. (2010). Ambient air pollution and hospital admission in Shanghai, China. Journal 537 of hazardous materials, 181(1), 234-240.

538 Chen, B., Kan, H., Chen, R., Jiang, S., \& Hong, C. (2011). Air pollution and health studies in 539 China - policy implications. Journal of the Air \& Waste Management Association, 61(11), 12925401299.

541 Ding, D., Zhu, Y., Jang, C., Lin, C. J., Wang, S., Fu, J., Gao, J., Deng, S., Xie, J., \& Qiu, X. 542 (2015). Evaluation of health benefit using BenMAP-CE with an integrated scheme of model and 543 monitor data during Guangzhou Asian Games. Journal of Environmental Sciences.

544 Fann, N., Lamson, A. D., Anenberg, S. C., Wesson, K., Risley, D., \& Hubbell, B. J. (2012s). 545 Estimating the national public health burden associated with exposure to ambient PM2. 5 and 546 ozone. Risk analysis, 32(1), 81-95.

547 Fann, N., Baker, K. R., \& Fulcher, C. M. (2012b). Characterizing the PM 2.5-related health 548 benefits of emission reductions for 17 industrial, area and mobile emission sectors across the US. 549 Environment international, 49, 141-151. 
550 Fann, N., \& Risley, D. (2013). The public health context for PM2. 5 and ozone air quality trends. 551 Air Quality, Atmosphere \& Health, 6(1), 1-11.

552 Fiore, A. M., Jacob, D. J., Bey, I., Yantosca, R. M., Field, B. D., Fusco, A. C., \& Wilkinson, J. G. 553 (2002). Background ozone over the United States in summer: Origin, trend, and contribution to 554 pollution episodes. Journal of Geophysical Research: Atmospheres, 107(D15).

555 Huang, D., Xu, J., \& Zhang, S. (2012). Valuing the health risks of particulate air pollution in the 556 Pearl River Delta, China. Environmental Science \& Policy, 15(1), 38-47.

557 Ito, K., De Leon, S. F., \& Lippmann, M. (2005). Associations between ozone and daily mortality: 558 analysis and meta-analysis. Epidemiology, 16(4), 446-457.

559 Jiandong, W., Shuxiao, W., Voorhees, S., Bin, Z., Jang, C., Jingkun, J., Fu, J., Ding, D., Zhu, Y., 560 \& Jiming, H. (2015). Assessment of short-term PM 2.5-related mortality due to different 561 emission sources in the Yangtze River Delta, China. Atmospheric Environment.

562 Kan, H., Wong, C. M., Vichit-Vadakan, N., \& Qian, Z. (2010). Short-term association between 563 sulfur dioxide and daily mortality: the Public Health and Air Pollution in Asia (PAPA) study. 564 Environmental Research, 110(3), 258-264.

565 Kwok, R. H., Fung, J.C.H., Lau, A. K., \& Fu, J. S. (2010). Numerical study on seasonal 566 variations of gaseous pollutants and particulate matters in Hong Kong and Pearl River Delta 567 Region. Journal of Geophysical Research: Atmospheres (1984-2012), 115(D16).

568 Lelieveld, J., Barlas, C., Giannadaki, D., \& Pozzer, A. (2013). Model calculated global, regional 569 and megacity premature mortality due to air pollution. Atmos. Chem. Phys, 13, 7023-7037.

570 Li, Y., Lau, A. H., Fung, J.C.H., Zheng, J. Y., Zhong, L. J., \& Louie, P. K. K. (2012). Ozone 571 source apportionment (OSAT) to differentiate local regional and super - regional source 572 contributions in the Pearl River Delta region, China. Journal of Geophysical Research: 573 Atmospheres (1984-2012), 117(D15).

574 Lu, X., Fung, J. C. H., \& Wu, D. (2015). Modeling wet deposition of acid substances over the 575 PRD region in China. Atmospheric Environment, 122, 819-828. 
576 Lu, X., Yao, T., Li, Y., Fung, J. C. H., \& Lau, A. K. H. (2016). Source apportionment and health

577 effect of NO x over the Pearl River Delta region in southern China. Environmental Pollution, $578 \quad 212,135-146$.

579 Lo, J. C., Lau, A. K., Fung, J. C. H., \& Chen, F. (2006). Investigation of enhanced cross - city 580 transport and trapping of air pollutants by coastal and urban land - sea breeze circulations.

581 Journal of Geophysical Research: Atmospheres (1984 - 2012), 111(D14).

582 Martenies, S. E., Wilkins, D., \& Batterman, S. A. (2015). Health impact metrics for air pollution 583 management strategies. Environment International, 85, 84-95.

584 Ministry of Health. People's Republic of China. China Health Statistics Yearbook 2011-2014. 585 Available from: http://www.nhfpc.gov.cn/zwgkzt/tjnj/list.shtml.

586 Ng, E., Yuan, C., Chen, L., Ren, C., \& Fung, J. C. H. (2011). Improving the wind environment in 587 high-density cities by understanding urban morphology and surface roughness: a study in Hong 588 Kong. Landscape and Urban Planning, 101(1), 59-74.

589 National Bureau of Statistics of China. China Statistical Yearbook 2011-2014. Available from: 590 http://www.stats.gov.cn/tjsj/ndsj/.

591 Qian, Z., He, Q., Lin, H. M., Kong, L., Liao, D., Yang, N., .. \& Xu, S. (2007a). Short-term 592 effects of gaseous pollutants on cause-specific mortality in Wuhan, China. Journal of the Air \& 593 Waste Management Association, 57(7), 785-793.

594 Qian, Z., He, Q., Lin, H. M., Kong, L., Liao, D., Dan, J., ... \& Wang, B. (2007b). Association of 595 daily cause-specific mortality with ambient particle air pollution in Wuhan, China. 596 Environmental research, 105(3), 380-389.

597 Shang, Y., Sun, Z., Cao, J., Wang, X., Zhong, L., Bi, X., Li, H., Liu, W., Zhu, T., \& Huang, W. 598 (2013). Systematic review of Chinese studies of short-term exposure to air pollution and daily 599 mortality. Environment international, 54, 100-111. 
600 Veira, A., Jackson, P. L., Ainslie, B., \& Fudge, D. (2013). Assessment of background particulate 601 matter concentrations in small cities and rural locations-Prince George, Canada. Journal of the 602 Air \& Waste Management Association, 63(7), 773-787.

603 Voorhees, A. S., Wang, J., Wang, C., Zhao, B., Wang, S., \& Kan, H. (2014). Public health 604 benefits of reducing air pollution in Shanghai: A proof-of-concept methodology with application 605 to BenMAP. Science of the Total Environment, 485, 396-405.

606 Wang, X., \& Mauzerall, D. L. (2006). Evaluating impacts of air pollution in China on public 607 health: implications for future air pollution and energy policies. Atmospheric Environment, 40(9), $608 \quad 1706-1721$.

609 Wang, Y., Zhang, Y., Hao, J., \& Luo, M. (2011). Seasonal and spatial variability of surface 610 ozone over China: contributions from background and domestic pollution. Atmospheric 611 Chemistry and Physics, 11(7), 3511-3525.

612 Wang, X., Chen, W., Chen, D., Wu, Z., \& Fan, Q. (2014). Long-term trends of fine particulate 613 matter and chemical composition in the Pearl River Delta Economic Zone (PRDEZ), China. 614 Frontiers of Environmental Science \& Engineering, 1-10.

615 Wong, T. W., Tam, W. S., Yu, T. S., \& Wong, A. H. S. (2002). Associations between daily 616 mortalities from respiratory and cardiovascular diseases and air pollution in Hong Kong, China. 617 Occupational and environmental medicine, 59(1), 30-35.

618 World Health Organization. (2000). Air quality guidelines for Europe.

619 Wu, Q., Wang, Z., Chen, H., Zhou, W., \& Wenig, M. (2012). An evaluation of air quality 620 modeling over the Pearl River Delta during November 2006. Meteorology and Atmospheric 621 Physics, 116(3-4), 113-132.

622 Wu, D., Fung, J.C.H., Yao, T., \& Lau, A. K. H. (2013). A study of control policy in the Pearl 623 River Delta region by using the particulate matter source apportionment method. Atmospheric 624 environment, 76, 147-161. 
625 Xie, X. (2011). The Value of Health: Applications of Choice Experiment Approach and Urban 626 Air Pollution Control Strategy. Peking University, Beijing, China.

627 Yao, T., Fung, J.C.H., Ma, H., Lau, A. K. H., Chan, P. W., Yu, J. Z., \& Xue, J. (2014). 628 Enhancement in secondary particulate matter production due to mountain trapping. Atmospheric 629 research, 147, 227-236.

630 Yang, G., Wang, Y., Zeng, Y., Gao, G. F., Liang, X., Zhou, M., ... \& Vos, T. (2013). Rapid 631 health transition in China, 1990-2010: findings from the Global Burden of Disease Study 2010. 632 The lancet, 381(9882), 1987-2015.

633 Yim, S.H.L., Fung, J.C.H., \& Ng, E. (2014) An assessment indicator for air ventilation and 634 pollutant dispersion potential in an urban canopy with complex natural terrain and significant 635 wind variations. Atmospheric Environment 94, doi:10.1016/j.atmosenv. 2014.05.044.

636 Zhang, Y., Huang, W., London, S. J., Song, G., Chen, G., Jiang, L., ... \& Kan, H. (2006). Ozone 637 and daily mortality in Shanghai, China. Environmental health perspectives, 1227-1232.

638

639

640

641

642

643

644

645

646

647 
Table 1: Summary of exposure-response coefficients for different pollutants

\begin{tabular}{|c|c|c|c|}
\hline Health Endpoints & Pollutants & ER(\%) for $10 \mu \mathrm{g} / \mathrm{m}^{3}$ increase & Reference and Methods \\
\hline \multirow[t]{4}{*}{ Total Mortality } & $\mathrm{SO}_{2}$ & $0.81(0.71,0.91)$ & \\
\hline & $\mathrm{NO}_{2}$ & $1.30(1.19,1.41)$ & Shang et al. (2013) \\
\hline & $\mathrm{O}_{3}$ & $0.48(0.38,0.58)$ & Meta-analysis \\
\hline & $\mathrm{PM}_{10}$ & $0.32(0.28,0.35)$ & \\
\hline \multirow[t]{4}{*}{ Cardiovascular Mortality } & $\mathrm{SO}_{2}$ & $0.85(0.70,1.00)$ & \\
\hline & $\mathrm{NO}_{2}$ & $1.46(1.27,1.64)$ & Shang et al. (2013) \\
\hline & $\mathrm{O}_{3}$ & $0.45(0.29,0.60)$ & Meta-analysis \\
\hline & $\mathrm{PM}_{10}$ & $0.43(0.37,0.49)$ & \\
\hline \multirow[t]{4}{*}{ Respiratory Mortality } & $\mathrm{SO}_{2}$ & $1.18(0.83,1.52)$ & \\
\hline & $\mathrm{NO}_{2}$ & $1.62(1.32,1.92)$ & Shang et al. (2013) \\
\hline & $\mathrm{O}_{3}$ & $0.73(0.49,0.97)$ & Meta-analysis \\
\hline & $\mathrm{PM}_{10}$ & $0.32(0.23,0.40)$ & \\
\hline \multirow[t]{3}{*}{ Total outpatient visits } & $\mathrm{SO}_{2}$ & $0.34(0.06,0.61)$ & \\
\hline & $\mathrm{NO}_{2}$ & $0.55(0.14,0.97)$ & Cao et al. (2009) \\
\hline & $\mathrm{PM}_{10}$ & $0.11(-0.03,0.26)$ & Generalized linear Poisson models \\
\hline \multirow[t]{3}{*}{ Total hospital admissions } & $\mathrm{SO}_{2}$ & $0.63(0.03,1.23)$ & \\
\hline & $\mathrm{NO}_{2}$ & $0.99(0.10,1.88)$ & Chen et al. (2010) \\
\hline & $\mathrm{PM}_{10}$ & $0.18(-0.15,0.52)$ & Generalized linear Poisson models \\
\hline
\end{tabular}

649

650

651

652

653

654

655

656

657

658 
Table 2: Negative health effects associated with ambient pollutants in the PRD

\begin{tabular}{|c|c|c|c|c|c|c|}
\hline & & All-cause mortality & Card-Mortality & Respir-Mortality & Outpatient Visits & Hospital Admissions \\
\hline & 2010 & $5,474(4,801-6,138)$ & $2,052(1,696-2,409)$ & 759 (539-976) & $1,874,987(332,853-3,352,044)$ & $59,015(2,839-113,844)$ \\
\hline \multirow[t]{4}{*}{$\mathrm{SO}_{2}$} & 2011 & $7,013(6,154-7,861)$ & $2,649(2,191-3,108)$ & $927(659-1,190)$ & $2,583,719(459,156-4,614,416)$ & $79,242(3,821-152,527)$ \\
\hline & 2012 & $5,851(5,133-6,560)$ & $2,160(1,786-2,536)$ & $892(634-1,146)$ & $2,335,056(414,746-4,172,428)$ & $73,262(3,529-141,173)$ \\
\hline & 2013 & $6,116(5,365-6,858)$ & $2,322(1,919-2,726)$ & $944(670-1,214)$ & $2,570,470(456,407-4,594,546)$ & $81,217(3,909-156,609)$ \\
\hline & 2010 & $11,578(10,608-12,546)$ & $4,645(4,047-5,208)$ & $1,382(1,129-1,624)$ & $4,031,586(1,036,086-7,056,708)$ & $122,768(12,625-228,924)$ \\
\hline \multirow[t]{4}{*}{$\mathrm{NO}_{2}$} & 2011 & $12,145(11,128-13,159)$ & $4,910(4,279-5,504)$ & $1,383(1,131-1,625)$ & $4,542,500(1,167,714-7,948,727)$ & $134,894(13,880-251,386)$ \\
\hline & 2012 & $12,153(11,135-13,168)$ & $4,803(4,185-5,384)$ & $1,596(1,304-1,875)$ & $4,927,459(1,266,567-8,623,085)$ & $149,623(15,393-278,885)$ \\
\hline & 2013 & $12,240(11,214-13,263)$ & $4,973(4,333-5,576)$ & $1,627(1,330-1,912)$ & $5,227,714(1,343,518-9,150,103)$ & $159,833(16,437-298,023)$ \\
\hline & 2010 & $9,317(7,389-11,216)$ & $3,126(2,027-4,149)$ & $1,351(914-1,783)$ & 1 & 1 \\
\hline \multirow[t]{4}{*}{$\mathrm{O}_{3}$} & 2011 & $11,471(9,102-13,803)$ & $3,880(2,517-5,146)$ & $1,585(1,074-2,090)$ & 1 & 1 \\
\hline & 2012 & $10,634(8,436-12,799)$ & $3,516(2,280-4,664)$ & $1,695(1,147-2,236)$ & 1 & 1 \\
\hline & 2013 & $9,583(7,601-11,537)$ & $3,257(2,111-4,322)$ & $1,547(1,047-2,042)$ & 1 & 1 \\
\hline & 2010 & $4,902(4,306-5,360)$ & $2,353(2,026-2,679)$ & $471(340-588)$ & $1,376,650(0-3,243,971)$ & $38,352(0-109,821)$ \\
\hline \multirow[t]{3}{*}{$\mathrm{PM}_{10}$} & 2011 & $4,057(3,563-4,437)$ & $1,964(1,691-2,236)$ & $372(269-465)$ & $1,221,889(0-2,881,476)$ & $33,217(0-95,281)$ \\
\hline & 2012 & $3,808(3,345-4,165)$ & $1,802(1,551-2,052)$ & $403(291-503)$ & $1,243,401(0-2,932,491)$ & $34,562(0-99,161)$ \\
\hline & 2013 & $5,396(4,741-5,900)$ & $2,623(2,259-2,986)$ & $577(417-721)$ & $1,859,196(0-4,380,135)$ & $52,000(0-148,832)$ \\
\hline
\end{tabular}

660

661

662

663

664

665

666

667

668

669 
Table 3: Four-year average of adverse health effects caused by air pollutants in each city

\begin{tabular}{|c|c|c|c|c|c|c|}
\hline & & All-cause mortality & Card-Mortality & Respir-Mortality & Outpatient Visits & Hospital Admissions \\
\hline & $\mathrm{HZ}$ & $77(67-86)$ & $29(24-34)$ & $11(8-14)$ & $29,419(5,209-52,727)$ & $924(44-1,793)$ \\
\hline & GZ & $1,872(1,642-2,098)$ & $703(581-825)$ & $270(192-347)$ & $718,590(127,698-1,283,398)$ & $22,464(1,083-43,240)$ \\
\hline & FS & $1,114(977-1,249)$ & $418(346-491)$ & 161(114-206) & $427,520(75,968-763,596)$ & $13,360(644-25,720)$ \\
\hline & DG & $673(590-755)$ & 253(209-297) & $97(69-125)$ & $256,807(45,562-459,376)$ & $8,036(386-15,522)$ \\
\hline \multirow[t]{10}{*}{$\mathrm{SO}_{2}$} & $\mathrm{JM}$ & $423(371-474)$ & 159(131-187) & $61(43-78)$ & $162,025(28,766-289,632)$ & $5,064(244-9,766)$ \\
\hline & SZ & $963(845-1,080)$ & $362(299-424)$ & 138(98-177) & $368,828(65,569-658,490)$ & $11,507(555-22,135)$ \\
\hline & ZS & $387(340-434)$ & $145(120-171)$ & $56(40-72)$ & $148,135(26,296-264,839)$ & $4,630(223-8,933)$ \\
\hline & ZQ & $95(84-107)$ & $36(30-42)$ & $14(10-18)$ & $36,546(6,475-65,457)$ & $1,146(55-2,220)$ \\
\hline & HK & $394(346-442)$ & $148(122-174)$ & $57(40-73)$ & $149,386(26,479-267,460)$ & $4,683(225-9,063)$ \\
\hline & ZH & $115(101-129)$ & $43(36-51)$ & $16(12-21)$ & $43,802(7,768-78,383)$ & $1,369(66-2,647)$ \\
\hline & $\mathrm{HZ}$ & $104(95-112)$ & $42(36-47)$ & $13(11-15)$ & $40,308(10,318-70,839)$ & $1,233(126-2,319)$ \\
\hline & GZ & $3,689(3,381-3,995)$ & $1,481(1,291-1,659)$ & $459(376-539)$ & $1,441,882(371,163-2,519,579)$ & $43,605(4,500-81,026)$ \\
\hline & FS & $1,743(1,597-1,889)$ & $700(610-785)$ & $218(178-256)$ & $679,768(174,669-1,190,007)$ & $20,598(2,118-38,420)$ \\
\hline & DG & $1,263(1,157-1,369)$ & $508(442-570)$ & $157(128-185)$ & $489,754(125,621-858,921)$ & $14,854(1,521-27,812)$ \\
\hline \multirow[t]{10}{*}{$\mathrm{NO}_{2}$} & $\mathrm{JM}$ & $465(426-504)$ & $187(163-210)$ & $58(47-68)$ & $180,814(46,356-317,268)$ & $5,488(561-10,286)$ \\
\hline & SZ & $2,349(2,153-2,545)$ & $944(823-1,058)$ & $292(238-343)$ & $913,173(234,780-1,597,677)$ & $27,628(2,844-51,472)$ \\
\hline & ZS & $595(545-645)$ & $239(208-268)$ & $74(60-87)$ & $231,228(59,348-405,258)$ & $7,004(718-13,096)$ \\
\hline & ZQ & $65(59-70)$ & $26(23-29)$ & $8(7-10)$ & $25,392(6,496-44,655)$ & $776(79-1,462)$ \\
\hline & HK & $1,581(1,449-1,713)$ & $635(554-712)$ & $196(160-231)$ & $612,400(157,398-1,071,804)$ & $18,544(1,907-34,571)$ \\
\hline & ZH & $175(160-190)$ & $70(61-79)$ & $22(18-26)$ & $67,595(17,323-118,649)$ & $2,049(209-3,842)$ \\
\hline & $\mathrm{HZ}$ & $988(784-1,188)$ & $332(216-440)$ & 149(101-196) & 1 & 1 \\
\hline & GZ & $1,858(1,474-2,237)$ & $624(405-829)$ & $280(189-369)$ & 1 & 1 \\
\hline & FS & $1,178(935-1,419)$ & $396(257-525)$ & $177(120-234)$ & 1 & 1 \\
\hline & DG & $1,473(1,169-1,773)$ & $495(321-657)$ & $222(150-293)$ & 1 & 1 \\
\hline \multirow[t]{10}{*}{$\mathrm{O}_{3}$} & $\mathrm{JM}$ & $827(657-996)$ & $278(180-369)$ & $124(84-164)$ & 1 & 1 \\
\hline & SZ & $1,638(1,299-1,971)$ & $550(357-730)$ & $247(167-326)$ & 1 & 1 \\
\hline & ZS & $525(416-631)$ & $176(114-234)$ & $79(53-104)$ & 1 & 1 \\
\hline & ZQ & $417(331-502)$ & 140(91-186) & $63(43-83)$ & 1 & 1 \\
\hline & HK & $1,052(835-1,267)$ & $354(229-469)$ & 159(107-210) & 1 & 1 \\
\hline & $\mathrm{ZH}$ & $294(234-354)$ & $99(64-131)$ & $44(30-59)$ & 1 & 1 \\
\hline & $\mathrm{HZ}$ & $237(208-259)$ & 114(98-130) & $24(17-30)$ & $74,400(0-175,534)$ & $2,062(0-5,922)$ \\
\hline & GZ & $1,271(1,116-1,389)$ & $611(526-696)$ & $128(92-159)$ & $399,457(0-940,717)$ & $11,082(0-31,689)$ \\
\hline & FS & $678(596-741)$ & $326(281-371)$ & $68(49-85)$ & $213,022(0-501,871)$ & $5,909(0-16,914)$ \\
\hline & DG & $599(526-655)$ & $288(248-328)$ & $60(43-75)$ & $187,984(0-443,178)$ & $5,217(0-14,955)$ \\
\hline \multirow[t]{6}{*}{$\mathrm{PM}_{10}$} & $\mathrm{JM}$ & $313(275-342)$ & $151(130-171)$ & $31(23-39)$ & $98,209(0-231,579)$ & $2,723(0-7,809)$ \\
\hline & SZ & $660(579-721)$ & $318(273-362)$ & $66(48-83)$ & $206,696(0-487,493)$ & $5,731(0-16,444)$ \\
\hline & ZS & $231(203-253)$ & $111(96-127)$ & $23(17-29)$ & $72,476(0-170,879)$ & $2,010(0-5,762)$ \\
\hline & ZQ & $133(117-146)$ & $64(55-73)$ & $13(10-17)$ & $41,880(0-98,758)$ & $1,162(0-3,332)$ \\
\hline & HK & $338(297-370)$ & $163(140-185)$ & $34(24-42)$ & $105,666(0-249,356)$ & $2,930(0-8,417)$ \\
\hline & ZH & $82(72-89)$ & $39(34-45)$ & $8(6-10)$ & $25,496(0-60,155)$ & $707(0-2,030)$ \\
\hline
\end{tabular}

671

672 
673 Table 4: Economic loss due to premature mortality and morbidity caused by ambient pollutants in the PRD (unit: millions of USD)

\begin{tabular}{lllll}
\hline & $\mathbf{2 0 1 0}$ & $\mathbf{2 0 1 1}$ & $\mathbf{2 0 1 2}$ & $\mathbf{2 0 1 3}$ \\
\cline { 2 - 5 } All-cause Mortality $^{\mathrm{a}}$ & $(12,167-21,295)$ & $(12,917-23,534)$ & $(13,185-24,457)$ & $(14,275-24,624)$ \\
Outpatient Visits $^{\mathrm{b}}$ & $(149-200)$ & $(188-226)$ & $(210-273)$ & $(244-326)$ \\
Hospital Admissions $^{\mathrm{b}}$ & $(174-231)$ & $(208-258)$ & $(234-289)$ & $(267-355)$ \\
Total $^{\mathrm{c}}$ & $(12,490-21,726)$ & $(13,313-24,018)$ & $(13,629-25,019)$ & $(14,768-25,305)$ \\
\hline
\end{tabular}

675

676 a: Economic loss was calculated by the VSL method.

677 b: Economic loss was calculated by the COI method.

678 c: The sum of the economic loss caused by all-cause mortality, outpatient visits and hospital admissions.

679

680

681

682

683

684

685 

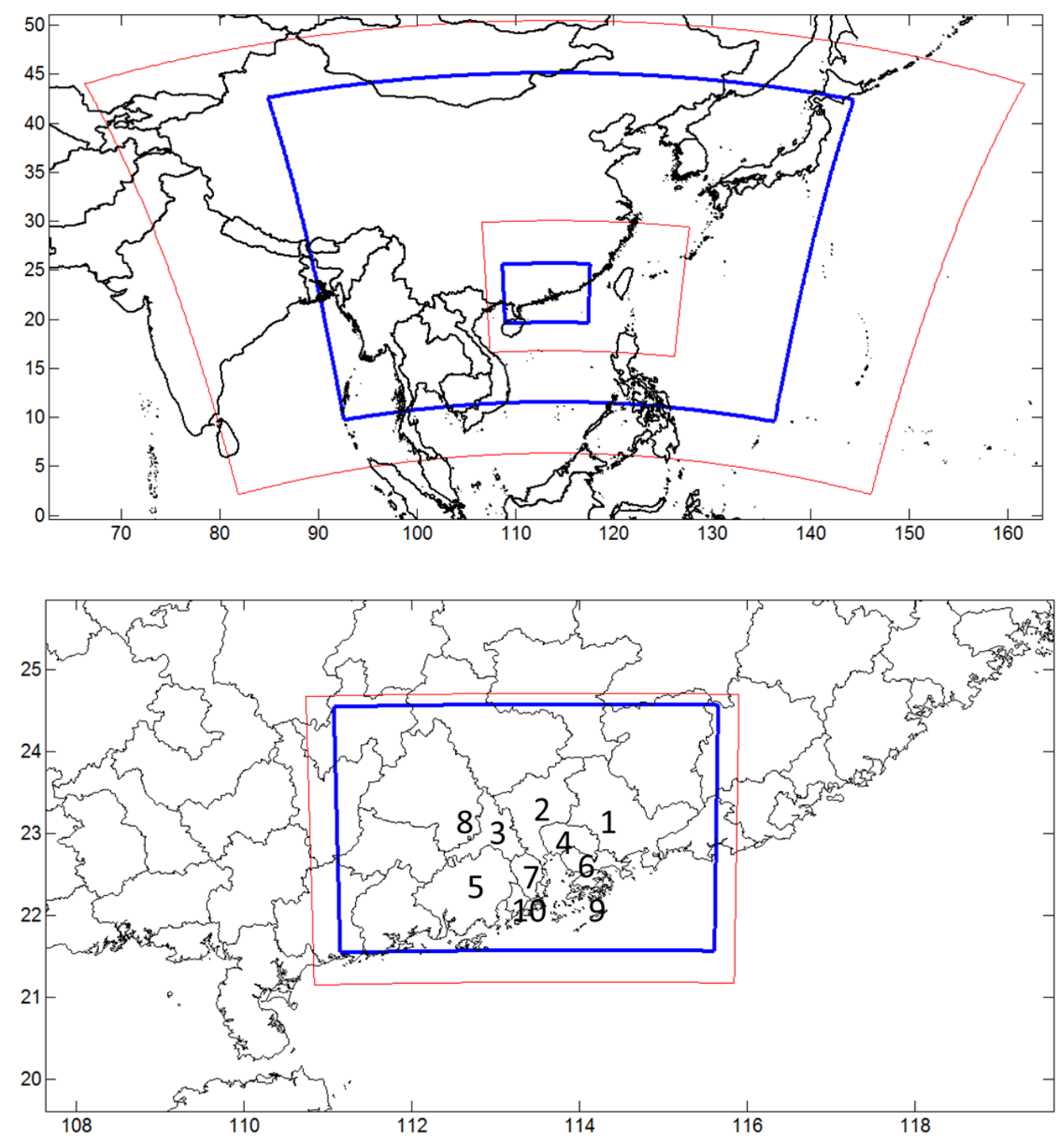

687 Figure 1: WRF (red) and CMAQ (blue) domain settings. 1, Huizhou (HZ); 2, Guangzhou (GZ); 3, Foshan 688 (FS); 4, Dongguan (DG); 5, Jiangmen (JM); 6, Shenzhen (SZ); 7, Zhongshan (ZS); 8, Zhaoqing (ZQ); 9 , Hong 689 Kong (HK) and 10, Zhuhai (ZH). 

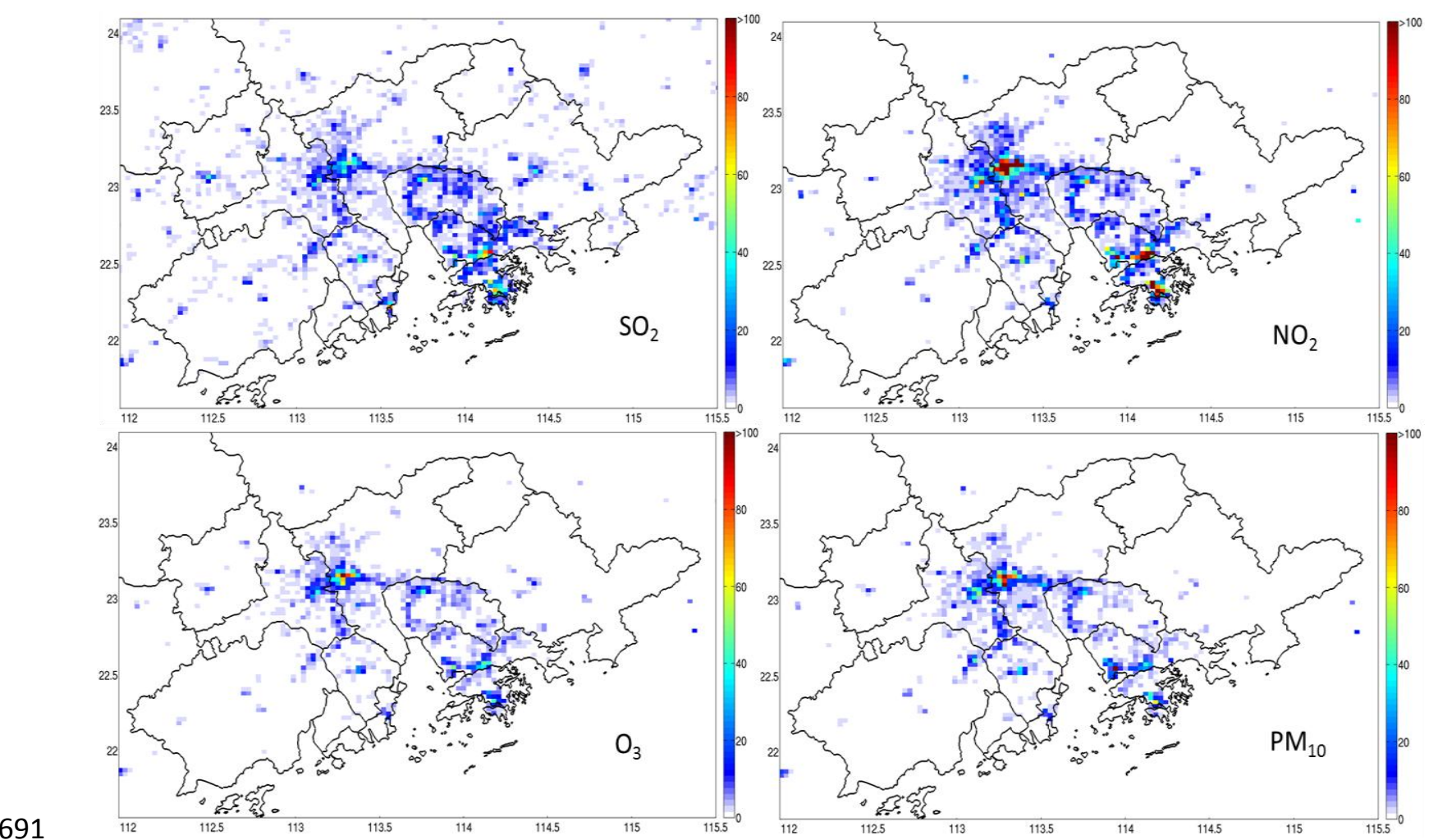

692

Figure 2: Spatial mapping of all-cause mortality for 2013 in the PRD.

693

694

695

696

697

698

699

700

701

702 


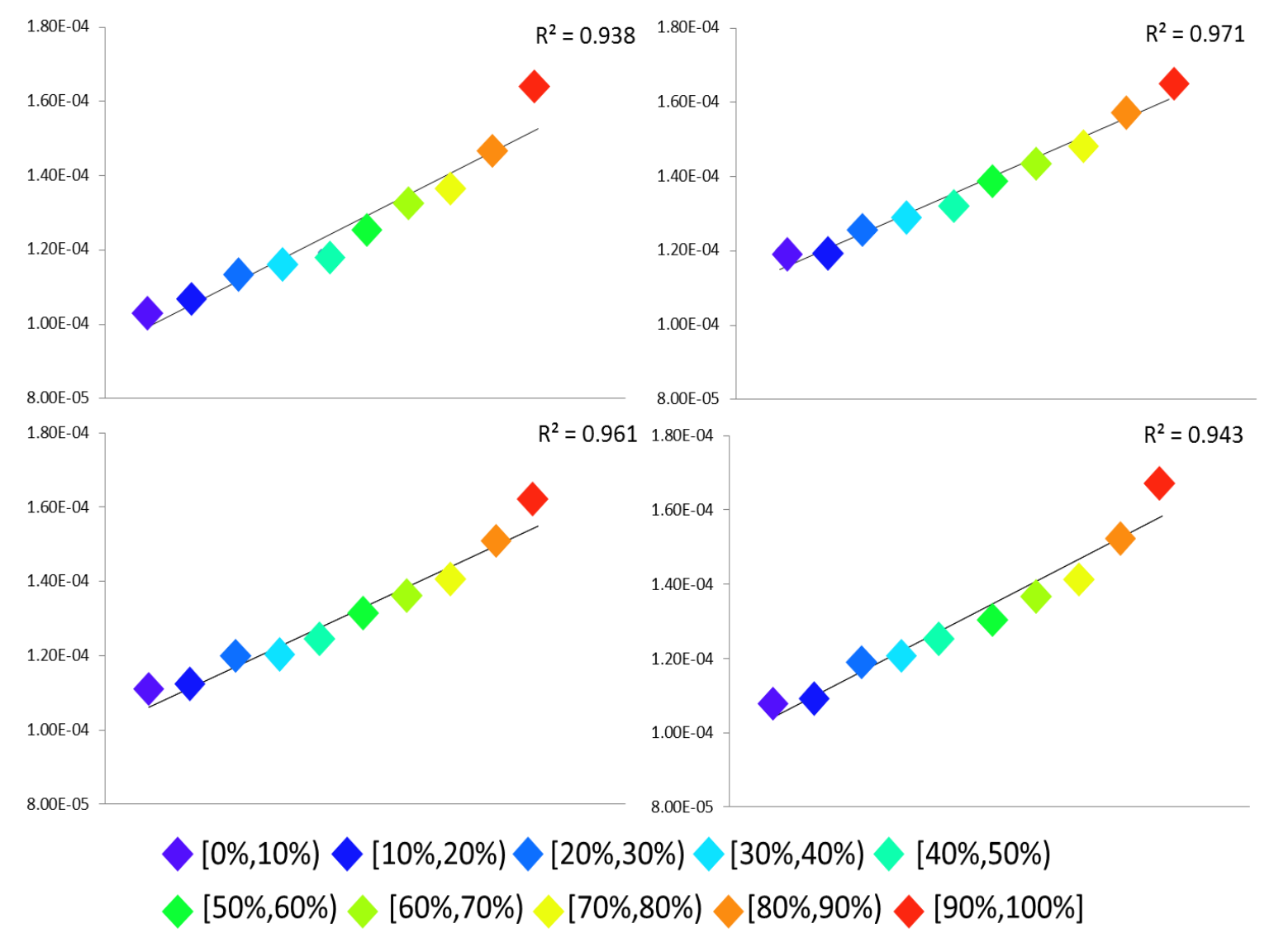

704 Figure 3: Correlation between the ratio of all-cause mortality to total population and urban 705 fraction. The percentage values in brackets represent the urban fraction.

706

707

708

709

710 

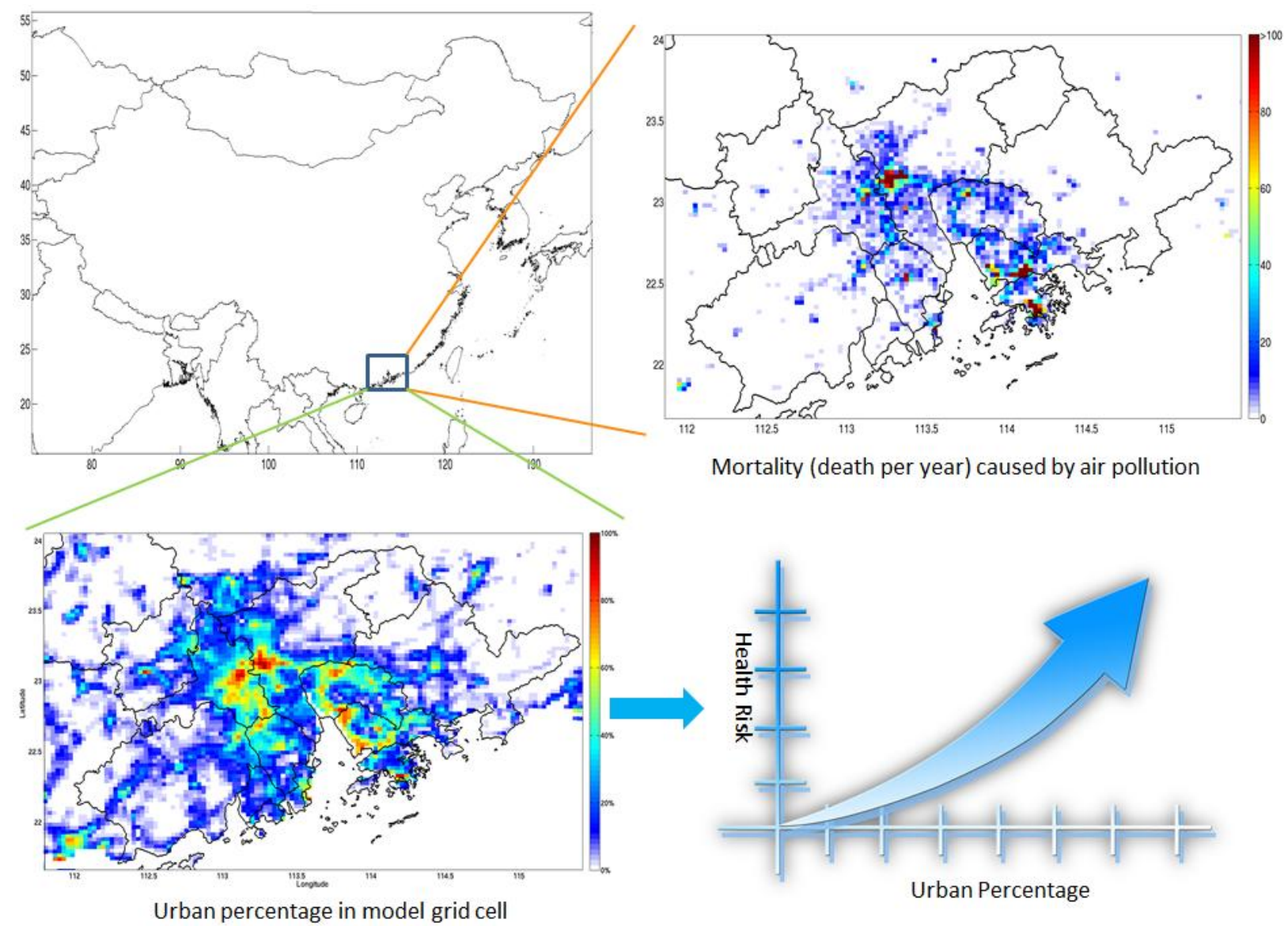